\title{
ACCOUNTING AND ANALYSIS: CURRENT CHALLENGES AND TRENDS
}

\author{
Valery V. Kovalev \\ St Petersburg State University, Russia \\ Vitaly V. Kovalev \\ St Petersburg State University, Russia
}

\begin{abstract}
In recent decades, the organization, administration and functioning of the methodology of accounting systems and analysis are under significant changes. In particular, the introduction of the American model of administrative and methodological management in the area of accounting is becoming a worldwide trend. The article deals with the main ideas in the formation of the accounting regulators' economic and methodological orientation, studied the relation of scientific and practical aspects of accounting. Particular attention is paid to the various interpretations of the financial analysis, as well as its relationship with modern accounting. It showed a modern trend in the transformation of the traditional financial reporting towards strengthening information-analytical component. Article logic assumes its structure, namely, the wording of the individual interconnected synthesis and definitions.
\end{abstract}

Keywords: conceptual framework, accounting, analysis

JEL code: M410

\section{Introduction}

According to the classification of the IMF, all countries are divided into two categories: (a) advanced economies, and (b) emerging markets and developing economies. At present, the global community is to align and harmonize the growth rates of emerging economies, which has the aim of raising the standard of living in these countries. The solution to this problem is not possible without harmonization of the basic methodological, methodical and organizational parameters of the economy as a whole, including such an important component of it, as accounting.

Existing country differentiation in accounting methodology and technique is supplemented by the emergence of problems related to the re-interpretation of the functional purpose of accounting as an essential component of any economic system. In particular, the accounting and the financial sector in recent years is undergoing significant changes related to the development and implementation of the ideas of conceptual framework of accounting, which implies a new understanding of how proper accounting and related fields, including analysis and financial analysis. This process has at least two distinctive features: (a) it is invariant with respect to any country; (b) it is far from being complete.

Russia is one of the most prominent representatives of emerging economies, where for many years accounting science and practice have evolved on the basis of principally other concepts than in advanced countries. The fundamental change of orientation in the political and economic development has led to the need of introducing a fundamentally new methodological basis in the field of accounting and reporting.

In this article the basic ideas related to rethinking the functional purpose, logic and principles of accounting and analysis are discussed in accordance with emerging trends that have developed in recent years both in advanced and developing economies. Ideas explained in the paper 
are particularly useful for researchers trying to understand the complexities of transformation methodology and accounting practices in developing economies.

1. Accounting and Finance. Traditionally accounting was seen as a kind of self-region economy. As the market economy - an economy based on financial contracts, the idea of close cooperation with the accounting and finance law becomes the primary. If the relationship with the law concerns mainly the regulatory aspects of accounting, the interpenetrating relationship with the finance belongs to the essential characteristic and methodological aspects of accounting. One explanation is obvious - users of the product of accounting activities are primarily related to the financial aspects of the business.

2. Purpose of accounting: control or communication. An essential feature of any economy is the pursuit of growth. This growth, by definition, cannot be flat, stable and, moreover, is constantly accelerating. To a large extent and the pace of its parameters depend on how comfortable business environment feels in general, and its backbone element - the company, in particular. This, at first glance, fairly obvious truth had in common, clearly articulated the recognition, in general, not too long ago (by the standards of the society and economic development), and the manifestation of this recognition is taken by the international community in the recent joint efforts and actions to streamline and optimize the conditions for the functioning of economic entities. Among these actions - the improvement and standardization of specific information support business. Modern business cannot function successfully in the information vacuum that is obvious, but even in the conditions of information stochastics. Completely eliminate the stochastic component of information support is not possible in principle, but there is a certain segment of identifiable unification and standardization.

In the middle of the $\mathrm{XX}$ century the basic objectives of financial accounting were viewed more broadly to include stewardship and decision usefulness for multiple users, including public utility regulators and public policy makers, not just stockholders and creditors (Nürnberg, 2012, p. 75).

The fact that a significant portion of the data, potentially carrying information, and (most importantly!) have the properties of reliability, relevance and verifiability, generated this particular system, and its main product (the public statements) is a universal information resource, which is of great interest for an extremely wide range of users. This resource has recently just become the object of attention not only accounting professionals, but, first of all, referred to potential users, which explains the significant changes in both the accounting and the principles of its interaction with the business environment. The essence of the changes - to change the functional accounting purposes: dominant control and analytical functions (assessment of resource allocation efficiency, controlled by economic subject) gave way to a dominant function of information and communication (provision of data, in the first place, potentially useful for making investment and financial decisions and, secondly, reducing the level of uncertainty in relations between independent economic entities). About the changes that have occurred is the fact that clearly shows a change in name of international accounting standards: if originally they were called as the International Accounting Standards (IAS), that since 2001 these standards began to be under the title of International Financial Reporting Standards (IFRS). And it is not just a name change. The main thing in the account (and it should reflect the standards) - not accounting technique itself, not a procedure, but the output product focused on the different categories of users, i.e. public financial reporting.

3. Interpretation of Accounting. The vast majority of scientists and experts, educated in Soviet-style training of economists, is inherent in the traditional understanding of accounting as an absolutely mundane practice-oriented discipline, which is in the mechanical performance of some technical procedures prescribed by the accounting regulator (in fact, the high- 
er authorities). The situation radically changed in the past quarter century. An obvious consequence of a fundamental change in the target destination is the accounting change and its interpretation: in modern economics accounting is appropriate to treat as the science about financial model of the company.

4. The effects of changes in accounting treatment. Focusing on information and communication functions of accounting resulted in the following:

- the development of a fundamentally different model of public reporting (financial supplement components of non-financial performance, reflecting the general economic and social importance of economic entities);

- unification of accounting standards in international and national contexts;

- the idea of the conceptual foundations of accounting as a kind of alternative to focus on professional standards of technical purpose;

- the introduction of accounting estimates, other than historical, in order to improve a predictive value of public reporting;

- the number of potential users;

- harmonization of relations between accountants and users of accounting control;

- develop and implement educational programs to improve professional-term (financial) literacy custom housing with the aim of improving the culture and skills to work with public statements.

5. Changes in accounting methodology and procedure. The essence of the changes is to implement the idea of a two-level system of professional standards, which include: a) a block of conceptual orientation standards (known as the conceptual framework of accounting) as the quintessence of the reliability concept and impartiality (true and fair view), based on the professional judgment of an accountant, his knowledge, skills, ethics; b) the unit of professional orientation standards defining principles of logic and reflection technique based on the types of situations and specific objects.

In addition to the organizational changes essential innovation in accounting procedure can be noted. In particular, we are talking about emerging accounting objects which did not exist previously. According to Zimmerman (2015, p. 487) traditional "nineteenth-" and "twentiethcentury firms" relied on large amounts of physical capital. "Twenty-first century firms" are now more knowledge-based, requiring human capital to generate their intangible assets. He also predicted that the role and place of intangible assets will grow much more rapidly. The share of these assets in the balance sheet will increase. Moreover, the basic principles of accounting can be modified in the future. In particular Srivastava (2014) argues that knowledgebased firms should have a lower correlation between their revenues and expenses than traditional firms because a larger fraction of their expenses are really investments in intangible intellectual property.

6. Accounting: the relationship between theory and practice. Deegan (2014) prepared a brief overview of theories of accounting and their correspondence with practice (Deegan, 2014 , pp. 7 - 16). Moreover the history of the accounting indicates that its evolution basically repelled by the requests and wishes of practice ${ }^{1}$. In part, this explains the rather common (especially in academic economics circles) interpretation of accounting as a purely practical technology, is hardly relevant to science. Researchers, and especially the representatives of the UK-USA school of accounting and finance applications, demonstrated the fallacy of such an interpretation. Understandable, and some of the obvious explanations put forward by ac-

\footnotetext{
${ }^{1}$ More information about this evolution in the USA can be found in (Zeff, 1999). This article served as the basis for the study of this trend on a global scale (Zeff, 2013).
} 
counting theorists: development of the concept of true and fair view, its informal implementation, forming a conceptual orientation of the standards, the adoption of the idea of having in account the uncertainty and variability, etc. are possible only with proper theoretical design of logic, methodology postulates and accounting principles as one of the most important components of the business environment.

7. Public reporting as the main accounting product. The accounting system has to deal with the huge volume of information data, that can in principle be focused on two important, but fundamentally different categories of users - internal and external (in relation to the company). Integration processes in the economy, its internationalization and the role of financial markets in the business environment significantly change the value of data, potentially useful for decision-making investment and financial nature. That is why public statements (its content, filling logic, analytical and forecasting capabilities, and so on.) get a high priority among the other possible products, potentially generated in the accounting system.

8. Public reporting and the user. Accountants make statements, not for a demonstration of its own, in a sense of endless possibilities with regard to the volume of potentially disclosed data. They have to not only take into account the constraints on the part of top management, but also focus on the users' requests. In addition, it is understood that reporting would be useful in making financial decisions. And this, in turn, presupposes the existence of a sufficiently broad class of intelligent and qualified users. In other words, under the present conditions dramatically increases the importance of training programs, not only accountants' and financiers', but also all participants' in the business environment.

New technologies bring to the accounting and audit professions new challenges. While the practice of Internet financial reporting has evolved rapidly, research has questioned the corresponding responsiveness of the auditing profession. In 2016 Fisher and Naylor (2016) study the existence and nature of an expectations gap that may have arisen in relation to the auditor's role and responsibilities with respect to IFR.

In developed countries (advanced economies), great importance in accounting has been given to various environmental reports. Initially, these studies only focused on representation in the accounting of environmental aspects of business activities. Nowadays, objectives of the study significantly increased and expanded. For example, we are talking about how accounting can affect climate change (see Linnenluecke, Birt and Griffiths (2015)).

9. Statements in the context of the analytical study financial decisions. Public reporting is done not for its own sake, but in order to be a strong argument in making decisions on investment projects (the answer to the question: Where to invest?) and financing (the answer to the question: How to get the money?). To this argument can be used properly, it is necessary not only and not so much to possess the skills of a primitive based on its basis of certain indicators and ratios, how to understand the logic of statements, the economic meaning of its articles, the principles of valuation reflected in her objects, and so on. Also another aspect is important: the statements can be demanded in fact, not formally only in the case if the user has sufficient culture with similar sources of information, owns the basics of reading and analyzing reports, understand its strengths and weaknesses, conventions and restrictions.

10. The analysis in economic science and practice. The term "analysis" is widely used in economic studies and in different contexts. Analysis predictably plays an important role in the management of the company as the basic unit of the modern economic system. That is why the application analytic direction in the science and practice of economic entities management has a long tradition. Historically, the evolutionary development of the application of economic analysis in Soviet economy and the West went in different directions. This section of the scientific knowledge and practical skills and techniques obtained a completely different 
meaning, and the essential procedural content. From the perspective of today, it is seen that in Russia the development of analytical direction is accompanied by various kinds of ambiguities, which in any case cannot explain some backwardness of national economic science. The root cause - the specific of political and economic system of the country existed for decades. This specific effected on the development of economic science, including in terms of the formation of different levels of economic targets and analyzing ways and means of achieving them.

11. The interpretation of the analysis: the UK-USA approach. In the writings of economists analysis as an independent direction in the sciences never identified, but the notion of this actively used mainly in three ways: a) as a synonym for 'research', 'detailed consideration', 'learning', 'knowledge' (generic name - an economic analysis); b) to designate a key element of management decision-making techniques (financial analysis, investment analysis, financial statement analysis, etc.); c) as an instrumental method (spectral analysis, covariance, harmonic, etc.). Of course, in the most general sense, option (a) is basic; one way or another, and it is embodied in the other two embodiments,

With regard to the US approach to the analysis, its generalization was the so-called ratio analysis, widely known now and which is the basis of educational materials for the analysis of financial statements (see, for example: White, Sondhi and Fried, 1994; Bernstein, Wild, 1996). In a sense, it can be assumed that the initiators of this analytical direction were American bankers since the 70s of XIX century. They began to demand from their customers, who apply for loans, the provision of financial statements. If at first the practice was of individualized and sporadic, whereas in the 1890s it has become normal for most banks, and soon led to the idea of public reporting (in terms of its accessibility to all interested parties) and the emergence of a variety of techniques for its reading and analysis (Foulke, 1961, pp. 13-19).

12. The analysis method as a knowledge economy. In the most general sense, economic analysis can be understood as research into the economy, interpreted, for example, as a set of relations arising in the process of production, exchange, distribution and consumption of goods. The famous Austrian economist Joseph Schumpeter (1883-1950), without giving a formal definition of economic analysis, outlined the term mastery of the technique of analysis (research study) in four areas: history, statistics, the "theory and economic sociology. In his view, the findings and conclusions in the course of any economic study should be formed with the mandatory sharing techniques of historical, statistical, theoretical and sociological analysis (see Schumpeter, 2006).

Collections of analytical procedures in the macro or micro system called the macro-economic and micro-economic analyzes, and one of the most famous in the scientific world of the corresponding instrumental descriptions presented in the fundamental monograph P. Samuelson (1915-2009) "Foundations of Economic Analysis" (interesting to note that the original version of this book was subtitled "operational value of economic theory) (see Samuelson, 1983).

13. The analysis of technology as a key element of acceptance of administrative solutions. In this case, we can talk about some embodiments, combining analytical activities (including calculations, evaluations, building models, etc.). They have a certain target orientation, the essence of which is to explain the situation in a particular area of the economy, or in the annex to the activities of some of the economic entity and the subsequent justification and (or) the optimization of some of the administrative decision of a particular nature (organizational, legal, investment, financial and others). Examples of such actions could be the analysis of investment attractiveness of the region, investment analysis of firms, analysis of financial statements of the economic entity, marketing analysis and others. In view of the exceptional diversity of objects (country, region, the economy as a whole, separate sphere of economy, 
industry, company, etc.) in respect of which can be performed analytical steps are often holds obvious uncertainty and vagueness in the interpretation and analysis of its essential filling. Therefore, the term "analysis" is often supplemented with different characteristics to be confirmed, which, however, does not always lead to certainty. In particular, highly-valued is the concept of "financial analysis". In economically developed countries, there are three main interpretations of the content of the financial analysis and financial analyst functions (see, for example, Harrington, Wilson, 1989). Thus, the American authors D. Bowlin, J. Scott and D. Martin consider the financial analysis in the context of the company's activity, i.e. the essence of the first approach is to understand the analysis as part of the work as a professional financial manager, responsible for the company for management of its cash flows (see, for example, Bowlin, Martin and Scott, 1990). The second approach is more oriented to professionals performing analytical procedures to the financial indicators, but limited in their information capabilities. In particular, one of the most common definitions within the framework of this approach can be seen in the work of B. Rice, who, under a financial analyst understands "any financial information user who wants to get this information in the process of economic decision-making and do not have access to the internal sources of information of the company" (Rees, 1990, p. 3). The third approach advocated by experts on the financial markets, which limit the scope of the financial analysis of the capital markets and it is believed that the "financial analysis includes the determination of levels of risk and expected return of individual financial assets or groups of them (Sharpe, Alexander and Bailey, 1997, p. 790).

14. Analysis method as a tool. Analysis can be understood not only as a series of specific actions, sometimes heterogeneous, and only united by one purpose, but also as a special detail algorithmic method which is potentially applicable in various fields of science and practice. Penetration of mathematics in the economy has intensified sharply with capital markets development. The presence of huge amounts of spatiotemporal information and stochastic nature of the data provided an excellent opportunity to practice in the application of mathematical tools. In the second half of the twentieth century in literature they described techniques of research in the economy with the use of special methods to study time series and space-time constellations, including spectral, covariance, harmonic, and factor analysis of variance. Some surge in the use of these methods, which came in the sixties and the eighties of the twentieth century, gradually faded. However, the potential to use these techniques naturally remains.

15. The analysis in the context of the company's activity - international tradition. In the second half of the XIX century in business practice, a number of countries began to form two analytical units of knowledge and skills. The first is actively developed by American experts and has been associated with the construction techniques of the analysis of the large companies that are directly related to capital markets and to act on them as either investors (investment of free cash), or the borrower (the attraction of financing sources). The constituent element of the analytical procedures was block methodology for assessing the financial condition of the companies primarily in terms of their owners as the third parties that do not have access to internal knowledge base. The second analysis unit represented by developments of German scientists and practitioners, has been focused on the managers of firms that have access to all the amounts of information stored in the company, and was designed to identify, assess and control the factors of increase of efficiency of the company operation due mainly to optimize its costs.

16. The ratio of the quantitative and qualitative analysis and modeling. It should be borne in mind at least two circumstances. Qualitative assessment is primary and dominant, and quantitative assessment - is secondary and subordinate. Neglect of this thesis often leads to the construction of an absolutely meaningless, not giving a coherent interpretation of economic indicators, models, and other classifications. Ill-conceived and unreasoned care in the quan- 
titative assessment can result in the production or insignificant or even simply erroneous conclusions and effects. For example, measures in the literature meets inclusion practices criticism of the item "Differed income in the "Equity" in the ratio analysis. The fallacy of the critics of this step is due to the fact that part of the item may include amounts attributable to liability rather than to future profits. Therefore, a simple reclassification of balance sheet items results in distortion of the values of a number of factors. To avoid distortion of said alleged possible by clarifying the structure of the item, followed by transferring to the "Equity section of only that part of it that can clearly be attributed to future earnings. In fact, given the argument is untenable. Even if you ignore the fact that the analysis is conducted according to public reports, which are not pre-supposes the inclusion in the balance every conceivable analytical transcript (this is not possible in principle), it is easy to understand that the simple reclassification ratio analysis is virtually no distortion does not occur at if only because of insignificance of the amount deferred. Therefore, attempt to identify and isolate the constituent components of this item it is likened to a "rat race - senseless in nature and result. In other words, engaged in the construction of classifications, indicators, models and procedures must first be guided by the principle of relevance and appropriateness, given by the following well-known maxim: the number came up with the devil, God came up with quality.

17. The effectiveness of analysis. Analytical reasoning and argumentation of re-investment decisions of a financial nature - it is usually a very costly exercise (especially with respect to significant investment projects of the company). So it seems quite natural question of the effectiveness analysis. In fact, it should be done in the broader sense - the analysis of the culture no matter how important to the financial position of the company is a problem requiring or suggesting some analytical steps. One key aspect of this culture can be formulated as the following thesis. The system management decision-making analysis should not be carried out for the sake of proper analysis - it must lead to certain consequences, i.e., to be effective. This means that any non-spontaneous decision must be justified by the possibility of a set of formalized and non-formalized analytical activities, but after the decision is made, it must be executed quickly, firmly, without hesitation and regret.

18. Consideration and analysis: the relationship logic. At first glance, a substantiation of such a relationship is not required and, moreover, it is evident. However, in Russia, more precisely in the Soviet practice account it was a fairly long period of artificial division. With the start of market reforms that period as a whole ended. At the same time, it is a new understanding of the role, nature and effectiveness of analytical procedures such as:

- to analyze the main thing is not to obtain some accurate estimates, it is impossible in principle, but the identification of trends and benchmarks;

- analysis procedure is costly, that is why it must be done if there is confidence that the expected benefits from the analytical calculations exceed the costs required for their implementation;

- the formation of a database in any case should not be to analyze and control the principle of "the more, the better (a literal adherence to this principle in in the 70s of the twentieth century led to the so-called "loss of relevance of data management accounting described by American researchers T. Johnson and R. Kaplan (see Johnson, Kaplan, 1991));

- complexity of algorithms and analytical models is not a guarantee of better conclusions;

- the results of the analysis should be clearly relevant and timely;

- any analysis is subjective by definition, and therefore the results cannot be considered as the sole and absolute argument in decision-making. 
19. Traditional financial statements and new models. In recent years in the international business environment, there is an obvious increase in the interest and attention to the quality of information and analytical support of activity of economic entities, and finding ways to improve it. This process was initiated in 1992 by Kaplan and Norton, who presented the socalled balanced scorecard (see Kaplan, Norton, 1992). Certain efforts are being made as the accounting community, and users of financial information. Accountants, together with financiers emphasize on the content, quality of the reporting (improving professional standards) and it is believed that any additional information can be presented in the relevant sections of the annual report. Other users advocate for the publication of an integrated report, understanding it as a systematic collection of data, allowing the user to get a detailed understanding of the company in the context of its relations with the partners and the public. Accounting data in this report may be present, but are only of secondary importance. In this regard, we note that the formation of any information base is a very expensive process. That is why, despite the constant criticism of the ongoing accounting, public financial reporting is likely to remain the backbone core of information flows that characterize the company in the coming decades. In other words, the first version of the development of information and analytical support for the business environment is quite acceptable. Therefore, not only outdated, but also more and more actualized the problem of harmonizing the interests of suppliers and users of public statements, which implies, inter alia, the improvement of a proper accountability (in composition, structure and quality characteristics), and the culture, skills and techniques of analytical work with it.

\section{Conclusion}

The theoretical analysis in the field of accounting and finance applications tendencies that was presented in the paper gives rise to the following main conclusions:

(a) in recent years, the dominant role of controlling function of accounting was replaced by the dominant role of its information and communication functions;

(b) the set of accounting standards (which actually can be named as function-oriented ones) is not enough to order and harmonize the methodological principles of accounting. This explains the need to adapt the ideas of conceptual framework of accounting to national accounting systems. In fact, it means that the conceptual framework of accounting should be regarded as the methodological foundation for constructing a set of national accounting; the last ones must be regarded as having a primarily functional, but not the methodological destination.

(c) the idea of distinction of accounting and analysis that existed in Russia (USSR) for decades, completely discredited itself. The analysis should be considered as an integral part of the whole complex accounting and analytical procedures.

\section{Literature}

Bernstein L. A., Wild J. J. (1999). Analysis of Financial Statements, 5th ed. McGraw-Hill Education.

Bowlin O. D., Martin J. D., Scott D. F. (1990). Guide to Financial Analysis, 2nd ed. Mc-Graw Hill.

Deegan C. (2014). Financial Accounting Theory, 4th ed. McGraw-Hill Education (Australia) Pty Ltd.

Fisher R. T., Naylor S. T. (2016). Corporate reporting on the Internet and the expectations gap: new face of an old problem. Accounting and Business Research, 46 (2), pp. 196-220.

Foulke R. A. (1961). Practical Financial Statement Analysis, 5-th ed. McGraw-Hill. 
Johnson H. T., Kaplan R. S. (1991). Relevance Lost: The Rise and Fall of Management Accounting. Boston, MA: Harvard Business Press.

Harrington D. R., Wilson B. D. (1989). Corporate Financial Analysis, 3rd ed. Richard D. Irwin.

Kaplan R. S., Norton D. P. (1992). The Balanced Scorecard: Measures that Drive Performance. Harvard Business Review, January-February, pp. 71-79.

Linnenluecke M., Birt J., Griffiths A. (2015). The role of accounting in supporting adaptation to climate change. Accounting \& Finance, 55 (3), pp. 607-625.

Nürnberg H. (2012). Objectives of financial reporting, aboriginal cost, and pooling of interests accounting. Accounting Historians Journal, 39 (2), pp. 45-80.

Rees B. (1990). Financial Analysis. Prentice Hall.

Samuelson P. (1983). Foundations of Economic Analysis. Harvard University Press, Enlarged Edition.

Schumpeter J. A. (2006). History of Economic Analysis. Taylor \& Francis e-Library.

Sharpe W. F., Alexander G. J., Bailey J. V. (1999). Investments. Prentice Hall.

Srivastava A. (2014). Why have the measures of earnings quality changed over time? Journal of Accounting and Economics, 57 (2-3), 196-217.

White G. I., Sondhi A. C., Fried D. (1994). The Analysis and Use of Financial Statements. John Wiley \& Sons, Inc.

Zeff S. A. (2013). The objectives of financial reporting: a historical survey and analysis. Accounting and Business Research, 43 (4), pp. 262-327.

Zeff S. A. (1999). The Evolution of the conceptual framework for business enterprises in the United States. Accounting Historians Journal, 26 (2), pp. 89-131.

Zimmerman J. L. (2015). The role of accounting in the twenty-first century firm. Accounting and Business Research, 45 (4), pp. 485-509. 